\title{
Advancing Global Health through Environmental and Public Health Tracking
}

\author{
Paolo Lauriola ${ }^{1, *}$, Helen Crabbe ${ }^{2}\left(\mathbb{D}\right.$, Behrooz Behbod ${ }^{3}{ }^{(D}$, Fuyuen Yip ${ }^{4}$, Sylvia Medina ${ }^{5}$, \\ Jan C. Semenza ${ }^{6}$, Sotiris Vardoulakis ${ }^{7}$ (), Dan Kass ${ }^{8}$, Ariana Zeka ${ }^{9,10}$, Irma Khonelidze ${ }^{11}$, \\ Matthew Ashworth ${ }^{12}{ }^{1}$, Kees de Hoogh ${ }^{13,14}$, Xiaoming Shi ${ }^{15}$, Brigit Staatsen ${ }^{16}$,
} Lisbeth E. Knudsen ${ }^{17}$, Tony Fletcher ${ }^{2,18}$, Danny Houthuijs ${ }^{16}$ and Giovanni S. Leonardi ${ }^{2,18}$ (])

1 National Research Council, Institute of Clinical Physiology, Unit of Environmental Epidemiology and Disease Registries, 56124 Pisa, Italy

2 Centre for Radiation, Chemical and Environmental Hazards, Public Health England, Didcot, Oxon OX11 ORQ, UK; helen.crabbe@phe.gov.uk (H.C.); Tony.fletcher@phe.gov.uk (T.F.);

Giovanni.leonardi@phe.gov.uk (G.S.L.)

3 Centre for Medical Education, Cardiff University, United Kingdom, Cardiff CF14 4XW, UK; behbodb@cardiff.ac.uk

4 Centers for Disease Control and Prevention, Atlanta, GA 30341, USA; fay1@cdc.gov

5 Direction of Environmental and Occupational Health, Santé Publique France, 94415 Saint Maurice, France; Sylvia.MEDINA@santepubliquefrance.fr

6 Scientific Assessment Section, European Centre for Disease Prevention and Control, 16973 Solna, Sweden, Sweden; JanC.Semenza@ecdc.europa.eu

7 National Centre for Epidemiology and Population Health, Research School of Population Health, Australian National University, Canberra 2601, Australia; sotiris.vardoulakis@anu.edu.au

8 Vital Strategies, New York, NY 10005, USA; dkass@vitalstrategies.org

9 Environmental Health and Epidemiology, Brunel University, London UB8 3PH, UK; Ariana.Zeka@brunel.ac.uk

10 Medical University Centre "Nene Teresa”, Rruga e Dibres, \#370 Tirana, Albania

11 National Center for Disease Control and Public Health, 0198 Tbilis, Georgia; i.khonelidze@ncdc.ge

12 Institute of Environmental Science and Research Limited, Kenepuru, Porirua 5240c, New Zealand; Matthew.Ashworth@esr.cri.nz

13 Swiss Tropical and Public health Institute, Basel, Switzerland, 4051 Basel, Switzerland; c.dehoogh@swisstph.ch

14 University of Basel, Basel, 4001 Basel, Switzerland

15 National Institute of Environmental Health, Chinese Center for Disease Control and Prevention, Beijing 100021, China; shixm@chinacdc.cn

16 National Institute for Public Health and the Environment, 3720BA Bilthoven, The Netherlands; Brigit.staatsen@rivm.nl (B.S.); Danny.Houthuijs@rivm.nl (D.H.)

17 Department of Public Health, Denmark University of Copenhagen, 1353 Copenhagen, Denmark; liek@sund.ku.dk

18 London School of Hygiene and Tropical Medicine, London WC1E 7HT, UK

* Correspondence: paolo.lauriola@gmail.com; Tel.: +39-335-5756961

Received: 5 February 2020; Accepted: 10 March 2020; Published: 17 March 2020

\begin{abstract}
Global environmental change has degraded ecosystems. Challenges such as climate change, resource depletion (with its huge implications for human health and wellbeing), and persistent social inequalities in health have been identified as global public health issues with implications for both communicable and noncommunicable diseases. This contributes to pressure on healthcare systems, as well as societal systems that affect health. A novel strategy to tackle these multiple, interacting and interdependent drivers of change is required to protect the population's health. Public health professionals have found that building strong, enduring interdisciplinary partnerships across disciplines can address environment and health complexities, and that developing Environmental and Public Health Tracking (EPHT) systems has been an effective tool. EPHT aims to merge, integrate,
\end{abstract}


analyse and interpret environmental hazards, exposure and health data. In this article, we explain that public health decision-makers can use EPHT insights to drive public health actions, reduce exposure and prevent the occurrence of disease more precisely in efficient and cost-effective ways. An international network exists for practitioners and researchers to monitor and use environmental health intelligence, and to support countries and local areas toward sustainable and healthy development. A global network of EPHT programs and professionals has the potential to advance global health by implementing and sharing experience, to magnify the impact of local efforts and to pursue data knowledge improvement strategies, aiming to recognise and support best practices. EPHT can help increase the understanding of environmental public health and global health, improve comparability of risks between different areas of the world including Low and Middle-Income Countries (LMICs), enable transparency and trust among citizens, institutions and the private sector, and inform preventive decision making consistent with sustainable and healthy development. This shows how EPHT advances global health efforts by sharing recent global EPHT activities and resources with those working in this field. Experiences from the US, Europe, Asia and Australasia are outlined for operating successful tracking systems to advance global health.

Keywords: environmental health; public health; global health; environmental public health tracking; surveillance; hazard; exposure and health outcomes; environmental epidemiology; health policy; prevention strategy

\section{Introduction}

Traditionally, environmental health problems have been addressed by controlling a single pollutant or exposure. However, today's complex environmental health problems require more innovative and holistic solutions that address not only a single pollutant or exposure, but the multifactorial effects of the environmental and environmental change on human health, and the systems that guide those effects. Considerations also need to be made at the individual, local, national and international levels.

In fact, issues facing 'planetary health' [1] and the related concept of 'ecological public health' [2] may be the ultimate 'wicked problems' of our time [3].

According to the Lancet Planetary Health's editor-in-chief Raffaella Bosurgi, "While public health is about health protection and health promotion within the health systems and global health looks at how to improve the health of populations worldwide, planetary health broadens this discussion by looking at the societies, civilisations and the ecosystems on which they depend. Planetary health offers an exciting opportunity to find alternative solutions for a better and more resilient future. It aims not only to investigate the effects of environmental change on human health, but also to study the political, economic, and social systems that govern those effects" [4].

Haines et al. described one holistic approach [5]: Planetary Health Watch, a proposed monitoring and forecasting system that links human health and environmental indicators in time and space, and which "... could improve the effectiveness of adaptation and mitigation strategies, assess progress towards nationally and internationally agreed targets, act as an early warning system, and hold decision-makers accountable. Indicators for inclusion in the system should be prioritised using transparent criteria, including relevance, sensitivity, sustainability, scalability, accuracy, economic viability, and consistency".

Accordingly, information on the pollution of air, water, soil, food as well as consumer products may be used in more than one way to recognise multiple links with health, wellbeing and environmental sustainability, and support activities directed at maximising these. For this to be feasible, appropriately aggregated and linked data needs to be shared with a wide range of users, who can both contribute and gain data and interpretative frameworks consistent with their respective sphere of activity. Legal, 
ethical, professional and technical aspects need to be addressed for such linkages to be feasible and for access to data by users who can contribute to relevant activities.

Environmental and Public Health Tracking (EPHT) could be a concrete tool to pursue such a need [6]. EPHT can be defined as: "The ongoing collection, integration, analysis, and interpretation of data about environmental hazards, exposure to environmental hazards, human health effects potentially related to exposure to environmental hazards. It includes dissemination of information learned from these data and implementation of strategies and actions to improve and protect public health" [7].

It is an approach that helps to increase the understanding of environmental public health and global health, improve the comparability of risks between different areas of the world, enable transparency and trust among citizens, institutions and the private sector, and inform preventive decision making.

This paper aims to show how EPHT advances global health efforts by sharing recent global EPHT activities and resources with those working in this field. We describe experiences of systems in the US, Europe, Asia and Australasia and outline the components for operating successful tracking systems to advance global health. It is noteworthy that, as a whole, these systems didn't implement new informative flows; however, first and foremost, they integrated those that were already running by integrating disciplines, institutions and professionals.

\section{Why and How Environment and Public Health Tracking Can Help Environment and Health Integration}

EPHT is also a helpful tool for strengthening the established Driving Forces, Pressures, State, Exposures, Health Effects and Actions (DPSEEA) framework [8]. EPHT promotes a systematic integration of the aforementioned DPSEEA components, taking into account both environmental and health parameters, in the context of realistic drivers, pressure and states.

EPHT aims to promote a resilient society by analysing complex datasets, addressing different audiences and supporting environmental health messaging tailored to each audience:

The public: information to support individual changes in attitudes and collective actions.

Professionals and stakeholders: tailored information to health professionals, land planners, environmental managers and researchers.

Decision-makers: integrated health and environmental information to inform decisions and create opportunities to reduce the multiplicative impacts associated with rapid urbanisation, globalization and climate/social/economic change.

Such general and generic categories also include resource managers, planners, economists, conservationists, indigenous and locally impacted communities, community developers and many other essential stakeholders. They are all strategically important, taking into account the dynamics which interrelates the two central issues on how population health may be improved: individual behaviour and social and economic factors $[9,10]$.

The EPHT approach strives to achieve its vision of "Healthy Informed Communities" by empowering environmental and public health practitioners, healthcare providers, community members, policymakers and others to make information-driven decisions that affect health while maintaining appropriate data protection measures [11]. We now need a global perspective, demanding "new coalitions and partnerships across many different disciplines" [12]. These challenging objectives should be delivered from the perspective of providing comprehensive integration within a "planetary" framework for environmental and public health outcomes; this must be considered the ultimate goal [13-15].

In summary, EPHT is an instrument which can support the cross-sectoral integration of information to assist decision-making in support of the greatest ambitions for global and planetary health outcome by means a comprehensive and ecological public health prevention approach. 


\section{The Concepts}

EPHT aims to merge, integrate, analyse and interpret environmental hazards, exposures and health data [16] (Figure 1) to provide information for public health decision-makers to reduce the environmental burden of disease.

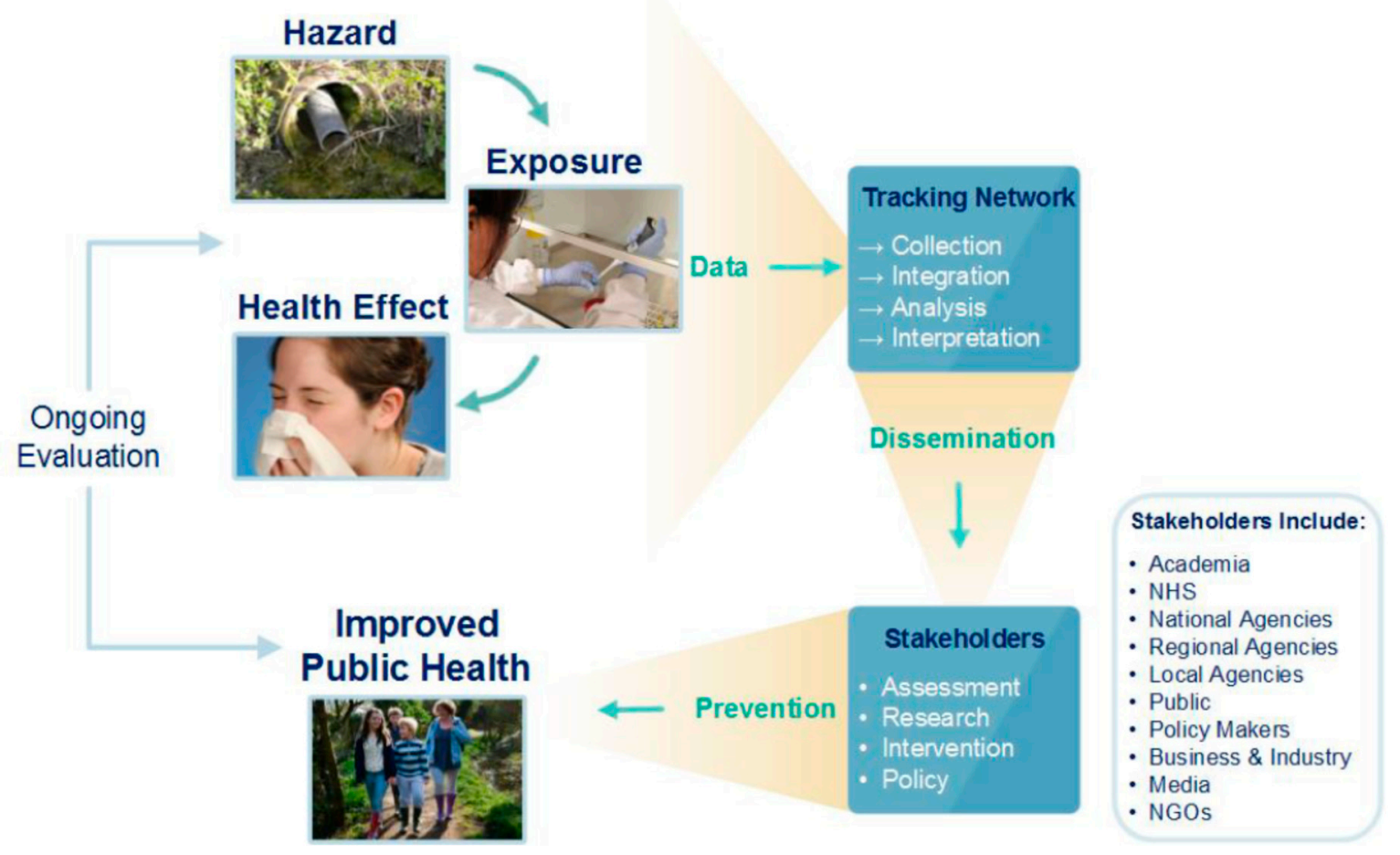

Figure 1. Environmental Public Health Tracking Components [17].

Accurate and timely surveillance data permit public health authorities to determine disease impacts and trends, recognise clusters and outbreaks, identify populations and geographic areas most affected, and assess the effectiveness of public health interventions [18]. By effectively linking standardised environmental and health data in an ongoing manner, and translating it into meaningful information (Figure 2), EPHT can help to protect the health of the public.

Thus, EPHT represents a modern surveillance system, the essence of proactive public health practice, with the ultimate goal to guide public health preventive action.

Ideally, exposure tracking includes the systematic measurement of harmful environmental agents to which individuals are exposed. Exposure tracking also helps evaluate the effectiveness of public health policies by monitoring changes over time. It needs to be closely coordinated with ongoing hazard tracking. This involves the monitoring of individuals, communities or population groups for the presence of an environmental agent or its metabolites by means of Human Bio Monitoring (HBM) investigations. Exposure (and hazard) tracking is sufficient for public-health surveillance when the causal link between exposure and health effect has been established with sufficient time latency between exposure and effect in cases where the concentration-response functions are known, and where exposure measurements are representative of the population's exposure. Examples of these situations include exposure to chemicals in drinking water [20]. 


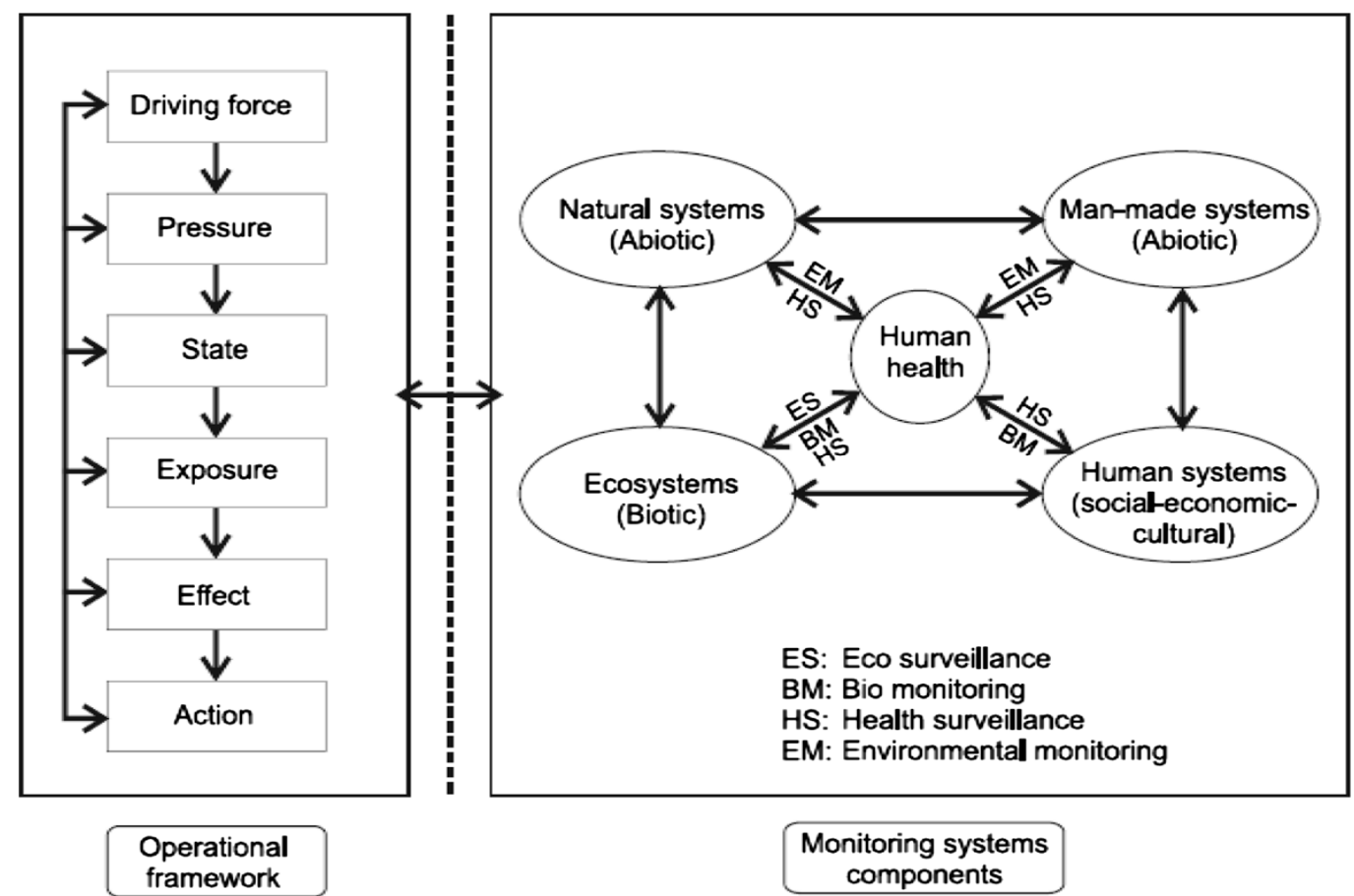

Figure 2. A conceptual framework for integrated environmental health monitoring [19].

The final component of environmental public health surveillance is health effects tracking, which represents traditional public health surveillance efforts. Examples of these situations are lead poisoning [21], hospital admissions for bronchiolitis [22] and some congenital malformations [23]. The key target of such a system is the primary prevention of chronic disease. Public health in the 21st century has the potential to recognise the environmental precursors of noncommunicable and communicable diseases. The case has been made in several specific instances, for example, where diabetes (Figure 3) has been associated with lifestyle factors and environmental exposure, including chronic exposure to cadmium and arsenic [24,25]; similar levels of causation apply to most noncommunicable diseases.

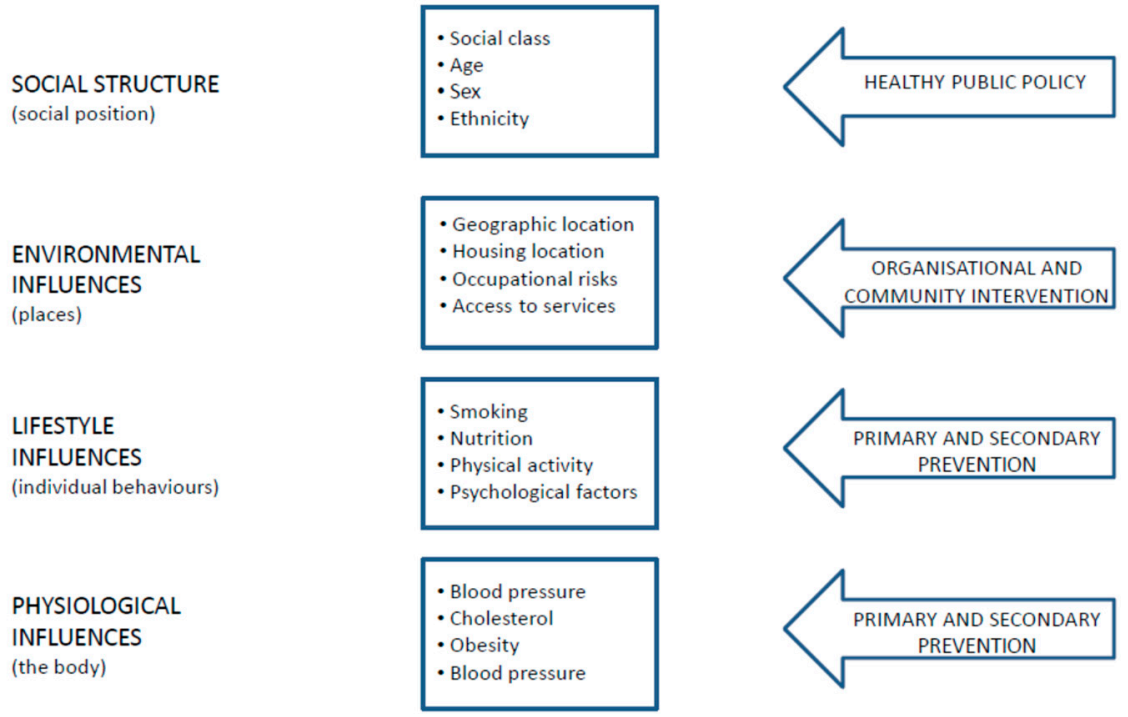

Figure 3. Levels of causation and corresponding types of intervention [26].

By highlighting the various potential levels of prevention interventions, the framework proposed for diabetes can be extended to other public health issues, as recognised by the WHO STEP-wise 
approach to the surveillance of noncommunicable diseases [26], where STEP established a conceptual framework that recognises the potential for prevention interventions at all levels; however, it has not yet achieved integration with the evidence base from environmental epidemiology. Therefore, improved coordination between noncommunicable and communicable disease programs with the evidence base from environmental epidemiology is called for, to put to use the available evidence on precursors of disease (i.e., environmental exposures) within a public health conceptual framework. In this way, it will be much more feasible to motivate and design the development of effective interventions at the appropriate level, to benefit from all available evidence and, thereby, to achieve the WHO goal of "Health in all policies" [27]. The two classical components of traditional surveillance include monitoring data on exposure and/or health outcomes [28].

A key distinction between EPHT and traditional surveillance is the emphasis on data integration across hazard, exposure and health information systems [3]; this could also be called "risk tracking", which involves quantifying and monitoring, at the population level, trends in the relationship between environmental hazards, exposures and health indicators.

To ensure the success of an EPHT programme, there is a need to involve several different constituencies in public health activities. Specifically, there is a demand for timely, accessible, accurate, representative and interpretable information about our environment and health for the public, media, researchers and policymakers, including input from specific interest and community groups, as well as the public health community at large.

\section{Some Experiences of Environmental Public Health Tracking}

Tracking activities have been conducted throughout the world. In many countries, they have adopted the label 'tracking' (e.g., the U.S., the U.K., Australia and China), whilst in others, different labelling has been used, not necessarily calling it 'tracking' (e.g., France, Italy, Brazil, Canada, New Zealand) [20], even though environmental health systems contain the same components of EPHT (Table 1), but without a clear and systematic strategy to integrate hazard, exposure and health data to be properly addressed to communication. Hereafter some experiences in which authors are involved are briefly described.

In 2000, the Pew Environmental Health Commission released a report on the state of environmental public health in the United States [7]. They recommended the development of a system to track and link environmental agents, exposures and related diseases because there was a lack of basic information that could document possible links between these factors. In 2002, the National Environmental Public Health Tracking Program (Tracking Program) was created at the Center for Disease Control and Prevention. Since its inception, the Tracking Program has worked closely with a community of funded state and local health departments to build capacity and infrastructure to develop the National Environmental Public Health Tracking Network (Tracking Network), an integrated network of environmental health surveillance data at the local, state and national levels.

The Tracking Network currently provides surveillance data on 20 different environmental and health topic areas (Figure 4) and there are over 420 different environmental health measures that are publicly available. The application of these data is key to supporting evidence-based decision making and public health actions within state and local programs to help promote healthy and informed communities. For example, at the national level, Strosnider et al. [29] examined the associations between ground-level ozone and fine particulate pollution and ER visits for asthma, chronic obstructive pulmonary disease (COPD) and respiratory infections. While previous studies focused on single cities, the authors leveraged the data available via the Tracking Program to look at the association between air pollution and respiratory ER visits across hundreds of U.S. counties. At the state and local levels, there have been efforts to use tracking program resources and/or data in establishing unique and diverse partnerships, developing innovative ways to use the data and resources, and identifying approaches to making the data more accessible, all to improve public health at the local, state and national levels [30]. 


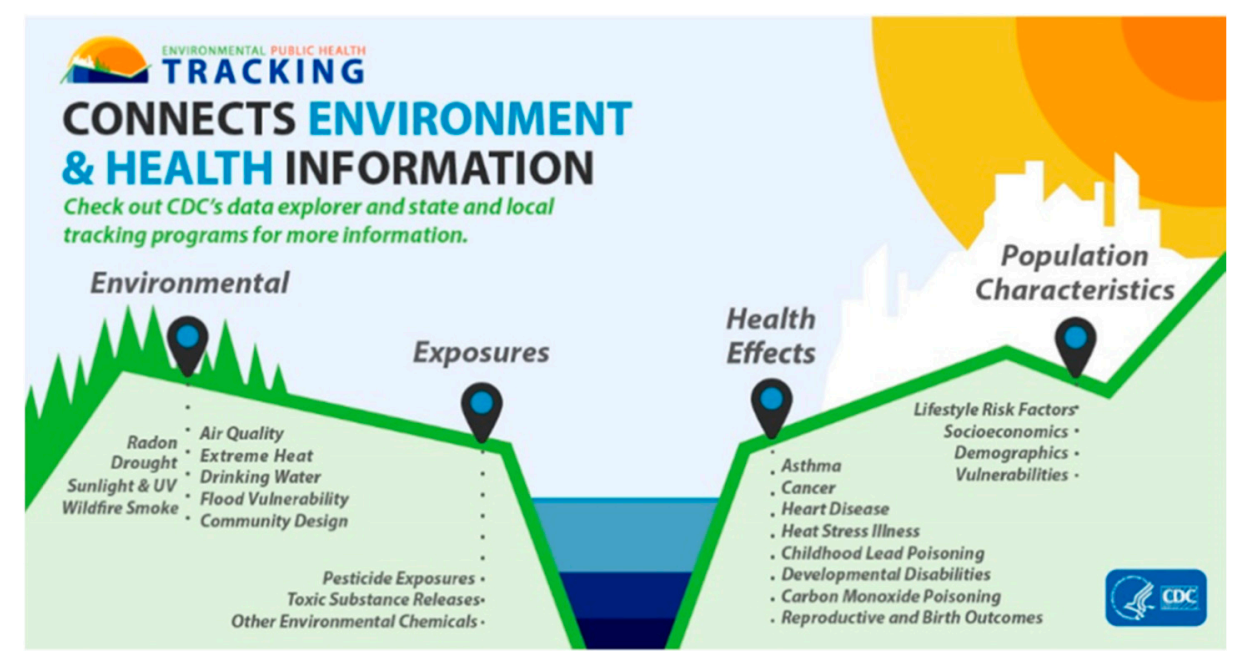

Figure 4. Environmental Health topics investigated by the US EPHT [31].

Meanwhile, EPHT in England [32] includes several programmes of surveillance of environmental hazards, exposures and health outcomes [33], e.g., population exposure estimation of arsenic in private water supplies [34], the burden of disease of carbon monoxide poisoning, [35] lead exposure in children [36,37], developing methods of risk prioritisation to support environmental public health interventions [38] and guidance for investigating non-infectious disease clusters from potential environmental causes. [39] The English EPHT programme has adopted an approach providing common governance for disparate themes, with the flexibility to establish surveillance structures and functions appropriate to specific information needs. Recent developments include developing national systems for enhanced air pollution exposure surveillance and weather data for public health use [33]. At a local level, the concepts of EPHT have been applied by Sandwell Metropolitan Borough Council, an urban local government in the Midlands, to identify the largest environmental public health concerns for the local authority area to help prioritise interventions [40].

In France, environmental-health surveillance has been built developing environmental-health dimensions of routine surveillance data systems. The overall concept of public-health surveillance at the national public health agency, Santé Publique France, formerly known as French Institut de Veille Sanitaire (InVS), is based on the observation that a complex changing environment creates new situations and emerging risks for which specific surveillance techniques are required (Figure 5).

Regarding specific surveillance, the European Apheis and Aphekom surveillance projects on air pollution and health [41], coordinated by Santé publique France, were designed to meet the information needs of environmental and public health institutions by performing health-impact assessments on the short- and long-term effects of air pollution over time using routine mortality and hospital admissions data. These initiatives were successful because they built on a Europe-wide collaborative network from the bottom up to stimulate cooperation and facilitate decision-making on the local and national levels [42]. In France, the surveillance programme on air pollution and health (Psas) has already celebrated its $23^{\text {rd }}$ anniversary, supporting French policies on air pollution at the local and national levels [43].

After the 2003 heatwave in France, Santé Public France developed SurSaUD [44] ${ }^{\circledR}$, a Syndromic Surveillance system (SyS) complementing traditional specific surveillance systems, capable of detecting new threats to public health as diverse as environmental phenomena or emerging infectious diseases. The Triple-S (Syndromic Surveillance Survey Assessment towards guidelines for Europe) project, also coordinated by Santé Public France, outlined SyS activities in Europe [45]. It assessed SyS, intending to produce guidelines for human and veterinary SyS in the Member States, as well as a proposal for a European SyS strategy. 


\section{Public Health Surveillance at Santé publique France}

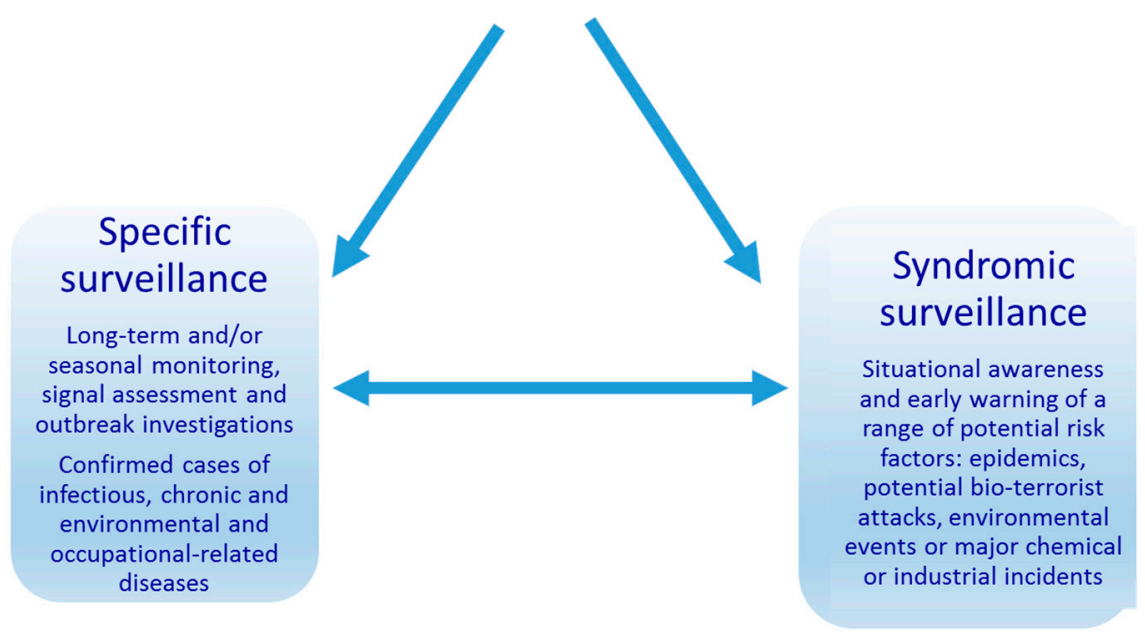

Figure 5. Public Health Surveillance at Santé publique France.

Examples of the complementarity between specific and SyS in environmental health in France include the Heat Health Watch Warning System, Cold-related diseases, Carbon Monoxide surveillance, Poisoning surveillance and Xynthia storm (2010) [46], and industrial accidents like the health monitoring of a gas leak at the Lubrizol company (2013) [47].

Table 1. Tracking activities around the globe that are collaborating in an international EPHT network (INPHET) [16].

\begin{tabular}{|c|c|c|}
\hline Country & Name/ Subjects & Leading Institution \\
\hline \multicolumn{3}{|c|}{ EPHT SYSTEMS } \\
\hline Australia [48] & $\begin{array}{l}\text { Currently developing a strategy for an Environmental Health Tracking System in } \\
\text { Victoria. A Driving Force-Pressure-Environmental Condition-Health } \\
\text { Impact-Action (DPEHA) conceptual framework is proposed for the proposed } \\
\text { Victorian EHTS. }\end{array}$ & $\begin{array}{l}\text { Environmental Protection Agency } \\
\text { (EPA) Victoria's Environmental Public } \\
\text { Health Unit }\end{array}$ \\
\hline China [49-51] & $\begin{array}{l}\text { The Chinese Environmental Public Health Tracking (CEPHT) project started in } \\
\text { September } 2015 \text { operated by the National Institute of Environmental Health, } \\
\text { Chinese Center for Disease Control and Prevention (NIEH, China CDC), } \\
\text { developing CEPHT's electronic data tracking system. Twenty-nine local Chinese } \\
\text { CDCs participate by reporting environmental hazard and health effects data } \\
\text { through the electronic system. }\end{array}$ & $\begin{array}{l}\text { National Institute of Environmental } \\
\text { Health (NIEH, China CDC) }\end{array}$ \\
\hline \multicolumn{3}{|c|}{ EPHT-EQUIVALENT SYSTEMS } \\
\hline \multicolumn{3}{|c|}{ North America } \\
\hline
\end{tabular}


Table 1. Cont.

\begin{tabular}{|c|c|c|}
\hline Country & Name/ Subjects & Leading Institution \\
\hline \multicolumn{3}{|c|}{ Europe } \\
\hline $\begin{array}{l}\text { European } \\
\text { Union }\end{array}$ & $\begin{array}{l}\text { 1. European Environment and Epidemiology (E3) Network [54], providing } \\
\text { access to climatic/environmental geospatial data for epidemiologic analysis } \\
\text { currently collected and analysed by a variety of European agencies, public } \\
\text { health institutes, and research organisations } \\
\text { 2. The system is an interactive database composed of country-level indicators } \\
\text { and regional assessments [55]. ENHIS indicators provide information on } \\
\text { exposures, health outcomes and policy actions related to the environment } \\
\text { and health priority areas for the European Region known as Regional Priority } \\
\text { Goals (RPGs) } \\
\text { The initiative is coordinating and advancing human biomonitoring in Europe. } \\
\text { HBM4EU is generating evidence of the actual exposure of citizens to } \\
\text { chemicals and the possible health effects to support policymaking [56]. }\end{array}$ & $\begin{array}{ll}\text { 1. } & \text { European Centre for Disease } \\
\text { Prevention and Control (ECDC) } \\
\text { 2. Environment and Health } \\
\text { Information System (ENHIS) } \\
\text { 3. European Human Biomonitoring } \\
\text { Initiative (HBM4EU) }\end{array}$ \\
\hline Italy & $\begin{array}{l}\text { 1. The main activity that has characteristics of ongoing surveillance is on } \\
\text { "Mesothelioma and Asbestos exposure tracking" [57]. There are also several } \\
\text { studies with the potential to become ongoing surveillance programmes. } \\
\text { 2. Sentieri [58], which describes the health profile of populations living in } \\
\text { contaminated sites, and provides elements for the design of ongoing } \\
\text { monitoring, that could have value across several countries [59,60] } \\
\text { 3. Moniter [61], dealing with incinerator risks } \\
\text { 4. EpiAir [62] for air pollution surveillance } \\
\text { 5. Environmental Health Task Force (EHTF) appointed by the Ministry of } \\
\text { Health (MoH), is underpinning a strategy to develop a framework which } \\
\text { includes local and national resources (underway). }\end{array}$ & $\begin{array}{ll}\text { 1. } & \text { National Institute of Health } \\
\text { 2. National Institute of Health } \\
\text { 3. } \\
\text { ARPA-ER } \\
\text { 5. } \\
\text { DEP-ARPAP } \\
\text { EHTT-MoH }\end{array}$ \\
\hline $\begin{array}{l}\text { The } \\
\text { Netherlands }\end{array}$ & $\begin{array}{l}\text { - Small Area Health Studies using health registries [63] } \\
\text { - Statistics Netherlands (CBS, Ministry Economic Affaires), Strategic Project } \\
\text { - } \quad \text { Health Care [63] } \\
\text { - } \quad \text { Aircraft noise annoyance in the vicinity of Amsterdam Schiphol Airport [65] }\end{array}$ & $\begin{array}{l}\text { National Institute of Public Health } \\
\text { and the Environment (RIVM) }\end{array}$ \\
\hline \multicolumn{3}{|c|}{ Eurasia } \\
\hline Georgia [63] & $\begin{array}{l}\text { A Multiple Indicator Cluster Surveys (MICS) on a representative sample of } \\
\text { children to study several demographic and health aspects over the last ten } \\
\text { years. Starting from lead biomonitoring in children, a national surveillance } \\
\text { programme is underway. } \\
\text { Considering the geographical and geopolitical situation of the region, the } \\
\text { experience in Georgia may lead to an initiative in collaboration with } \\
\text { neighbouring countries, with the potential to establish a regional Eurasia hub } \\
\text { for EPHT, based on a network established at a recent EU funded } \\
\text { TAIEX workshop. }\end{array}$ & $\begin{array}{l}\text { National Center for Disease Control } \\
\text { and Public Health (NCDC-PH) }\end{array}$ \\
\hline \multicolumn{3}{|c|}{ Pacific Region } \\
\hline New Zealand & $\begin{array}{l}\text { 1. A system reports on a range of environmental hazards, with the additional } \\
\text { synthesis of the environmental burden of disease for second-hand smoke } \\
\text { exposure. Also working on developing environmental burden of disease } \\
\text { reports for ultraviolet light exposure and lead }(\mathrm{Pb}) \text { exposure. }[66,67] \\
\text { 2. Reporting provides weekly communicable disease surveillance and outbreak } \\
\text { surveillance reporting to New Zealand regional health authorities. }\end{array}$ & $\begin{array}{l}\text { 1. Massey University } \\
\text { 2. Institute of Environmental } \\
\text { Science and Research [68] }\end{array}$ \\
\hline $\begin{array}{l}\text { Kingdom of } \\
\text { Tonga [69] }\end{array}$ & $\begin{array}{l}\text { - Vector and vector-borne disease surveillance that includes meteorological and } \\
\text { Southern Ocean oscillation index data, and relates to the climate change } \\
\text { monitoring data collected in Tonga } \\
\text { - Water quality, water-borne disease and infection monitoring }\end{array}$ & Ministry of Health, Kingdom of Tonga \\
\hline $\begin{array}{l}\text { South Pacific } \\
\text { Region [70] }\end{array}$ & $\begin{array}{l}\text { - The Pacific Public Health Surveillance Network (PPHSN) is a voluntary } \\
\text { network of countries and organisations dedicated to the promotion of public } \\
\text { health surveillance and appropriate response to the health challenges of } 22 \\
\text { Pacific Island countries and territories (PICTs). It includes six service } \\
\text { networks: PacNet, LabNet, EpiNet, PICNet, the Pacific Syndromic } \\
\text { Surveillance System and the Strengthening Health Interventions in the } \\
\text { Pacific-Data for Decision Making (SHIP-DDM) capacity } \\
\text { development programme. }\end{array}$ & $\begin{array}{l}\text { Secretariat for the Pacific Community } \\
\text { (SPC) }\end{array}$ \\
\hline
\end{tabular}

There are many other examples of tracking activities carried out across the world (Table 1). These countries have shared their experiences of developing EPHT and form an international network [16].

In summary, we have outlined some global examples of environmental and health information integration, which highlights the notion that factual and common constraints can be overcome.

Such reviews of tracking and similar programmes around the world indicate that EPHT has the potential to facilitate the translation of science into public health practice and go beyond just providing data or information to users and stakeholders, helping generate intelligence that is sufficiently mature 
to be translated into actions [30]. This recognition led to the creation of the International Network on Public Health and Environment Tracking (INPHET) in 2013 [16].

Following meetings in Europe and the USA [16], efforts have been made to identify INPHET goals aligned with broader public health needs while retaining a focus on environmental health surveillance. This network operates voluntarily, with political and intellectual independence, promoting scientific rigour in environmental and public health decision-making. Several workshop and symposiums have been held to demonstrate its application [16].

However, the EPHT tool is not yet widely available in most regions which are vulnerable to environmental hazards in the world. Some efforts are underway in some Low- and Middle-Income Countries (LIMCs) such as Georgia [63], Turkey [63], Ghana, Ethiopia, Myanmar and Tonga, to show its application and usefulness.

More generally, a detailed and comprehensive description of those experiences could be helpful to realise that it is possible to implement such organisation, but the 'governance' of these programmes must also be tailored according to the social, cultural and political setting. Such an issue is supported by the efforts of INPHET.

\section{Extending EPHT Capacity}

The core infrastructure of EPHT within national public health agencies can deliver both the capacity to support ongoing concerns regarding hazardous pollutants and chemicals in drinking water, land, food and air, and new perspectives on the central value of ecological and social factors in affecting health and wellbeing in the course of multiple transitions currently experienced by society. The latter perspectives are explored initially in research partnerships between national public health agencies operating EPHT programmes and academic or other relevant research institutions. An example is the establishment of "Health Protection Research Units" in the UK, providing 5-year research programmes on topics such as Health Impact of Environmental Hazards [71] contributing methods for indoor air tracking, and Environmental Change and Health [72] addressing the role of ecological factors such as those affecting the distribution of vectors [73], climate variability affecting infectious diseases [74-76] or coastal changes affecting toxin-producing algae [77], as well as social factors affecting use of green spaces and related health benefits [78].

Novel interpretative frameworks could first be tested and documented in a "experimental" research setting, in studies codesigned and coproduced with public health agencies including EPHT operators $[79,80]$. This process facilitated appreciation of the value of the mentioned alternative interpretative frameworks as components of the routine operations of public health agencies including provision of advice and EPHT. For some topics, the usual delay between research and practice could be considerably shortened by these arrangements. This type of collaboration illustrates the capacity for EPHT to act as a fast transmission chain from existing information frameworks to their transformation into public health tools capable of systematic consideration and integration of ecological and social factors. This process means that EPHT may support mainstream public health operations and partnerships in making a transition toward more appropriate consideration of ecological and social factors in health protection and health improvement activities.

The process briefly summarised here for the case of EPHT in England has been applied in different forms to other settings and countries.

While the specific modalities vary in terms of form and amount of research fund allocation and its relationship with EPHT, a common pattern is emerging where EPHT connects with a range of research approaches and results, and aims to integrate them into everyday environmental health activities.

\section{The Future}

The continued development of EPHT activities around the world will help support improvements in environmental health. In aligning with the WHO Health in All Policies (HiAP) strategy [81], EPHT can provide a beneficial approach to public health practice in an era of diminishing resources and 
increasing demand, where scientific evidence can support interventions in a range of sectors, such as transportation, housing, energy, waste management, land use and climate change. However, action at international, national, regional and local levels must be taken to improve and protect global health as soon as knowledge and intelligence become appropriately mature to be able to effectively address, monitor and evaluate progress against public health risks. Many actions to improve the environment can have multiple health co-benefits, such as policies promoting active travel in cities which can reduce air pollution and noise from vehicle traffic and, at the same time, help improve physical activity and respiratory and cardiovascular health [82].

EPHT will also promote strong and enduring relationships and partnerships across all tiers of the local and national government, across public health and environmental agencies, and with both the private sector and the general public/NGO community. Along this line, the focus should be placed on the issues described in Section 5.

\section{Governance: Principles to Direct EPHT}

The collective experience of EPHT operators in several countries points to several fundamental principles for the good governance of such an operation. Such principles have developed over decades, and therefore, may not appear innovative; however, they are valid based on a widely experienced practice.

Sustainability: This principle refers to the need for any surveillance/tracking system to produce useful outputs on an ongoing basis. Such a need is founded on minimal human resources, skills and capability to be maintained. It also relates to the sustainability of inputs of data feeds and the ability to produce regular outputs of surveillance, such as annual reports.

Competence: In principle, any public health surveillance/tracking system requires leadership by a public health agency, operation by staff trained in epidemiology and public health information systems.

Integration: A worthwhile goal for an EPHT system is to contribute to addressing the overall preventable burden of disease. Starting from a topic within this broad agenda will require integration of complex environmental, exposure and health information.

Accountability: An EPHT has the potential to produce influential information for decision-makers and officials in a range of public agencies. Typically, this will require a multidisciplinary collaboration where competencies from several departments or organisations are contributing to the same agreed surveillance/tracking goal. For these reasons, accountability via a clear and an agreed governance approach is necessary (i.e., through appropriate Terms of References).

Transparency: Specific tasks of members of a surveillance/tracking working group can be allocated by a mechanism agreed within the working group itself and in consultation with general policies and practices. This will typically involve adopting a governance tool for recognising the task and role of the group.

In other words, governance should essentially aim to federate data providers and standardise the methods of data collection and analysis at the level of each established partnership. The above governance principles are largely consistent with dimensions recognised by OCAP principles (ownership, control, access, and possession) [83].

\section{Ethical Dimensions}

The four principles of beneficence, nonmaleficence, justice and respect for autonomy are included in ethics guidelines drafted for public health professionals. They are particularly relevant in the field of EPHT because any activity which is capable of changing the extent of emissions or pollution necessarily requires a careful balancing of several contrasting considerations in the interest of optimally addressing the needs of society. Although the following do not provide an exhaustive account of how the principles are applied, they can be used as a framework to support ethical decision making. 


\subsection{Beneficence}

\subsubsection{Confidentiality and Privacy}

Maintaining the confidentiality of personally identifiable data (PID) is a key feature of any research study, and is also relevant to the management of data assets part of a public health surveillance programme such as EPHT. It is important that participants are treated with respect and dignity at all times [84], although EPHT mostly will benefit from assembling data assets from data collected for other reasons, thus not adding a burden to participants while being careful to preserve anonymity.

\subsubsection{Data Storage and Data Sharing.}

Hard (quantitative) and soft (intelligence) data [85] need to be stored securely, should be anonymised and archived for a period appropriate to the purpose; as EPHT focuses on noncommunicable disease, holding aggregated data over decades would be necessary for comparisons over time (20-30 years).

\subsection{Nonmaleficence.}

\subsubsection{Minimise Risk, Disruption and Harm}

Nonmaleficence is achieved by assembling data assets for an EPHT programme that minimises risk, disruption and harm to both study participants and the source population. These risks should be fully assessed, quantified and mitigated or minimised if possible. If a risk is discovered as part of EPHT-based analyses that might adversely affect well-being, it should be communicated to the individuals/populations concerned [84].

\subsubsection{Precautionary Principle}

Another example of nonmaleficence is the 'Precautionary Principle'. This essentially means that "When human activities may lead to harm that is scientifically plausible but uncertain, actions shall be taken to avoid or diminish that harm [84,86,87], though not advocated by all" [88].

\subsection{Autonomy (Including Informed Consent).}

\subsubsection{The Distinction between Data for Research and Public Health Surveillance}

An important consideration when applying for ethics approval is to establish the status of the EPHT programme and data assets. Accurate definitions may be necessary to discern the level of ethical approval required [89].

\subsubsection{Institutional Review Boards/Research Ethics Boards}

There are numerous names for groups of people officially established to decide whether a research project can ethically and legally be approved, such as Institutional Review Boards, Research Ethics Boards, and Research Ethics Committees (RECs). Their constitution may differ across time and jurisdictions, with various experts brought in if required by the type of study being assessed [90], but they should always contain representatives of the population involved [84].

\subsubsection{Informed Consent}

The International Society of Environmental Epidemiology (ISEE) Guidelines state that there must be full disclosure of relevant aspects of the study, such as its purpose and any potential hazards, to the study participants before explicit prior, documented informed consent is obtained. [84]. 


\subsection{Justice}

\subsubsection{EPHT Obligations to Society}

Obligations to society involve ensuring objectivity in the process of designing of an EPHT data asset and reporting of the outcome of specific analyses, as well as the overarching obligation to deliver only high-quality public health surveillance, supported by relevant research which will materially improve the understanding of a particular subject.

\subsubsection{EPHT Programme Obligations to Funders/Sponsors, Employers and Colleagues}

These obligations need to be identified early in the research process and involve the population concerned at all stages of the study, from initiation to publication [84]

\section{Examples of Priorities for EPHT Activities}

Taking into account what can be reasonably and practically implemented in the near future, and the needs of many countries in particular in LMICs, we suggest some issues to which efforts should be devoted. They could be some realistic field in which to apply the 'holistic' framework of EPHT because of a new and emerging environmental health challenge relevant to planetary health.

\subsection{EPHT in Urban City Planning}

Evidence-based interventions to develop an integrated approach to improve air quality and climate change adaptation in cities are being implemented. EPHT can help evaluate urban policies to combat extreme temperatures, air pollution, noise, promote green spaces, sustainable urban development, etc. as urged for example by the WHO [91], Climate Clean Air Coalition's Urban Health Initiative [92] and Healthy Polis Initiative [93].

\subsection{EPHT in Industrially Contaminated Sites}

Development of industry and its products has brought many benefits to modern societies, including a reduction in deprivation. Conversely, it has also generated a large amount of hazardous materials, in many cases where some of the most disadvantaged and vulnerable communities live. Such activities may harm health and wellbeing due to chemical exposure and socio-economic deprivation [94]. Industrially contaminated sites (ICS) represent a long-term legacy of past and current development, a probable lasting cause of preventable noncommunicable disease and a living reminder of the inherent lack of sustainability of the linear economy. There is an urgent need to identify the most suitable interventions aimed at prevention of ill-health in affected communities, to facilitate better social and economic development while minimising exposure to harmful compounds associated with ICS.

\subsection{EPHT and Socio-Economic Development}

In LMICs, there is a strong need for economic development. Historical patterns worked well economically for the high-income world but resulted in burdening the environment and health across the globe and in particular for LMIC. The solution requires a technological and intellectual transition in all countries; an alternative route to economic prosperity that preserves resources and limits carbon emissions is urgently needed. EPHT can be a helpful tool with which to work towards informed, healthy, sustainable and equitable prosperity in these developing economies.

\section{Conclusions}

Environmental public health issues are becoming increasingly complex. Globalisation, population growth and overconsumption are placing significant stresses on the environment and health. 
Socioeconomic diversity across the world must be taken into account, which is closely related to a geographic diversity in data/information availability and ability to use these resources to inform decision-making.

EPHT can contribute to reducing socioeconomic and environmental inequality across communities, countries and regions, by sharing experiences, knowledge, information and data. Hence, EPHT networking activities must support local, regional, national and global improvements in the environment and reductions in its impact on health, which will be achieved by strengthening and sharing a common philosophy among public health professionals working in environmental health around the world. It requires governance efforts for the integration of a wide range of scientific disciplines and people, from institutional decision-makers and officials in public health agencies to representatives of the civil society. In sum, this article:

- Indicates that difficulties encountered in integrating disciplines, professional profiles and institution can be effectively overcome by focusing on the final goal of environmental health prevention and promotion. Some successful stories are herein described in different countries, either under the banner of EPHT or not, but with the same function;

- Introduces the experience of countries, where such an approach is being implemented nationally, whilst taking the opportunity to collaborate with other countries (hubs);

- Focuses on some lessons learned in performing such experiences, first and foremost from the ethical point of view;

- Discusses the concept of EPHT, aiming at sharing opportunities to develop it towards more ambitious goals (planetary health);

- Clarifies the context in which such an ecological public heath tool might be essential to attaining global health goal, but also to moving towards the ultimate goal of Planetary Health.

- In other words, it aims at creating a community of health professionals and researchers who could share experiences, proposals, and thoughts in the field of practical, effective environmental health prevention and promotion.

Author Contributions: Conceptualization Ideas: P.L., H.C., B.B., F.Y., S.M., J.C.S, S.V., D.K., A.Z., I.K., M.A., K.d.H., X.S., B.S., L.E.K., T.F., D.H. and G.S.L.; funding acquisition: G.S.L. and P.L.; supervision: P.L., G.S.L. and H.C.; writing-original draft preparation: P.L., H.C., B.B., F.Y., S.M., J.C.S., S.V., D.K., A.Z., I.K., M.A., K.d.H., X.S., B.S., L.E.K., T.F., D.H. and G.S.L.; writing-review and editing preparation: P.L., H.C., B.B., F.Y., S.M., J.C.S., S.V., D.K., A.Z., I.K., M.A., K.d.H., X.S., B.S., L.E.K., T.F., D.H. and G.S.L. All authors have read and agreed to the published version of the manuscript.

Funding: This work was partially funded by the National Institute for Health Research Health Protection Research Unit (NIHR HPRU), Health Impact of Environmental Hazards at King's College London in partnership with Public Health England (PHE) in collaboration with Imperial College London, London, UK; and by the NIHR HPRU in Environmental Change and Health at the London School of Hygiene and Tropical Medicine in partnership with PHE, and in collaboration with the University of Exeter, University College London, and the Met Office.

Acknowledgments: The authors are grateful for the support to this work provided by the Scientific Committee of the International Network on Public Health \& Environment Tracking.The authors thank the reviewers for improvements and suggestions made on earlier drafts to improve the article. We also thank the various countries listed for providing examples of tracking in countries.

Conflicts of Interest: The authors declare no conflict of interest.

\section{References}

1. Whitmee, S.; Haines, A.; Beyrer, C.; Boltz, F.; Capon, A.G.; de Souza Dias, B.F.; Ezeh, A.; Gong, P.; Head, P.; Horton, R.; et al. Safeguarding Human Health in the Anthropocene Epoch: Report of The Rockefeller Foundation-Lancet Commission on Planetary Health. Lancet 2015, 386, 1973-2028. [CrossRef]

2. Rayner, G.; Lang, T. Ecological Public Health: Reshaping the Conditions for Good Health; Routledge: Abingdon, UK, 2012. 
3. Behbod, B.; Lauriola, P.; Leonardi, G.; Crabbe, H.; Close, R.; Staatsen, B.; Fletcher, T.; Knudsen, L.E.; de Hoogh, K.; Medina, S. Environmental and public health tracking to advance knowledge for planetary health. Eur. J. Public Health 2016, 26, 900. [CrossRef]

4. What's the Difference? Planetary Health Explained. Available online: https://www.globalhealthnow.org/201709/whats-difference-planetary-health-explained (accessed on 14 March 2020).

5. Haines, A.; Hanson, C.; Ranganathan, J. Planetary Health Watch: Integrated monitoring in the Anthropocene epoch. The Lancet 2018, 2, e141-e143. [CrossRef]

6. Planetary Health meeting Edinburgh 2018 (Side Session). Available online: http://inphet.org/news_and_ links/side-event-at-planetary-health-conference-edinburgh-2018/ (accessed on 14 March 2020).

7. McGeehin, M.A.; Qualters, J.R.; Niskar, A.S. National Environmental Public Health Tracking Program: Bridging the Information Gap. Environ. Health Perspect. 2004, 112, 1409-1413. [CrossRef] [PubMed]

8. Reis, S.; Morris, G.; Fleming, L.E.; Beck, S.; Taylor, T.; White, M.; Hurley, F.; Depledge, M.H.; Steinle, S.; Sabel, C.E.; et al. Integrating health and environmental impact analysis. Public Health 2015, 129, 1383-1389. [CrossRef] [PubMed]

9. Baum, F.; Fisher, M. Why behavioural health promotion endures despite its failure to reduce health inequities. Sociol. Health Illn. 2014, 36, 213-225. [CrossRef]

10. Logan, A.C.; Prescott, S.L.; Katz, D.L. Golden Age of Medicine 2.0: Lifestyle Medicine and Planetary Health Prioritized. J. Lifestyle Med. 2019, 9, 75-91. [CrossRef]

11. National Environmental Public Health Tracking: About the Program. Available online: https://www.cdc. gov/nceh/tracking/about.htm (accessed on 14 March 2020).

12. Horton, R.; Lo, S. Planetary health: A new science for exceptional action. Lancet 2015, 386, 1921-1922. [CrossRef]

13. Buse, C.G.; Oestreicher, J.S.; Ellis, N.R.; Patrick, R.; Brisbois, B.; Jenkins, A.P.; McFarlane, R.A.; Mckeller, K.; Kingsley, J.; Gislason, M.; et al. Public health guide to field developments linking ecosystems, environments and health in the Anthropocene. J. Epidemiol. Community Health 2018, 72, 420-425. [CrossRef]

14. Gillingham, M.P.; Halseth, G.R.; Johnson, C.J.; Parkes, M.W. The Integration Imperative Cumulative Environmental, Community, and Health Effects of Multiple Natural Resource Developments; Springer: Berlin/Heidelberg, Germany, 2016.

15. Parkes, M.W.; Allison, S.; Harder, H.G.; Hoogeveen, D.; Kutzner, D.; Aalhus, M.; Chiasson, A.; Adams, E.; Beck, L.; Brisbois, B.; et al. Addressing the Environmental, Community, and Health Impacts of Resource Development: Challenges across Scales, Sectors, and Sites. Challenges 2019, 10, 22. [CrossRef]

16. INPHET: International Network on Public Health \& Environment Tracking. Available online: http: //inphet.org/ (accessed on 14 March 2020).

17. Environmental public health surveillance system. Available online: https://www.gov.uk/government/ publications/environmental-public-health-surveillance-system (accessed on 14 March 2020).

18. California Policy Research Centre, University of California. Strategies for Establishing an Environmental Health Surveillance System in California. A Report of the SB702 Expert Working Group. 2004. Retrieved. Available online: http://www.ehib.org/ehib/www.ehib.org/project84a2.html?project_key=EHSS01 (accessed on 11 December 2008).

19. Liu, H.Y.; Bartonova, A.; Pascal, M.; Smolders, R.; Skjetne, E.; Dusinska, M. Approaches to integrated monitoring for environmental health impact assessment. Environ. Health 2012, 11, 88. [CrossRef] [PubMed]

20. Workshop Report for the Modena meeting of the International network on Public Health and Environment Tracking (INPHET) Workshop Title: Environmental \& Public Health Tracking to Advance Environmental Health Held on the 14th and 15th May 2014, in Modena, Italy. Available online: http://www.epiprev.it/sites/ default/files/INPHET_Modena-Workshop-report-Final-v1.0-20141007.pdf (accessed on 14 March 2020).

21. Chandramouli, K.; Steer, C.D.; Ellis, M.; Emond, A.M. Effects of early childhood lead exposure on academic performance and behaviour of school age children. Arch. Dis. Child. 2009, 94, 844-848. [CrossRef] [PubMed]

22. Shay, D.K.; Holman, R.C.; Newman, R.D.; Liu, L.L.; Stout, J.W.; Anderson, L.J. Bronchiolitis-Associated Hospitalizations among US Children, 1980-1996. JAMA 1999, 282, 1440-1446. [CrossRef] [PubMed]

23. Dolk, H. EUROCAT: 25 years of European surveillance of congenital anomalies. Arch. Dis. Child. Fetal. Neonatal. 2005, 90, F355-F358. [CrossRef]

24. Peng, Q.; Harlow, S.D.; Park, S.K. Urinary arsenic and insulin resistance in US adolescents. Int. J. Hyg. Environ. Health 2015, 218, 407-413. [CrossRef] 
25. Son, H.S.; Kim, S.G.; Suh, B.S.; Park, D.U.; Kim, D.S.; Hong, Y.S.; Sakong, J. Association of Cadmium with diabetes in middle aged residents of abandoned metal mines: The first health effect surveillance for residents in abandoned metal mines. Ann. Occup. Environ. Med. 2015, 27, 20. [CrossRef]

26. Noncommunicable diseases and their risk factors. Available online: http://www.who.int/ncd_surveillance (accessed on 14 March 2020).

27. Adelaide Statement on Health in All Policies; World Health Organization: Geneva, The Switzerland, 2010; Available online: http://www.who.int/social_determinants/hiap_statement_who_sa_final.pdf (accessed on 14 March 2020).

28. Wegman, D.H. Hazard Surveillance. In Public Health Surveillance; Baker, W., Halperin., E.L., Eds.; Van Nostrand Reinhold: New York, NY, USA, 1992.

29. Strosnider, H.M.; Chang, H.H.; Darrow, L.A.; Liu, Y.; Vaidyanathan, A.; Strickland, M.J. Age-Specific Associations of Ozone and Fine Particulate Matter with Respiratory Emergency Department Visits in the United States. Am. J. Respir. Crit. Care Med. 2019, 199, 882-890. [CrossRef]

30. Yip, F.Y. Environmental Public Health Tracking: From Data to Action. J. Public Health Manag. Pract. 2017, 23, S1-S3. [CrossRef]

31. National Environmental Public Health Tracking: Tracking: Better Information for Better Health. Available online: https://www.cdc.gov/nceh/tracking/BetterInfoBetterHealth.htm (accessed on 14 March 2020).

32. Public Health England. Environmental Public Health Surveillance System (EPHSS). 2019. Available online: https://www.gov.uk/government/publications/environmental-public-health-surveillance-system/ environmental-public-health-surveillance-system-ephss (accessed on 14 March 2020).

33. Crabbe, H.; Leonardi, G. Environmental Public Health Tracking in England. Report on Recent Activities; December; In 2018. Available online: https://assets.publishing.service.gov.uk/government/uploads/system/ uploads/attachment_data/file/797812/PHE_EPHT_Activities_Report_2018.pdf (accessed on 14 March 2020).

34. Crabbe, H.T.; Fletcher, R.M.; Close, M.J.; Watts, E.L.; Ander, P.L.; Smedley, N.Q.; Verlander, M.; Gregory, D.R.; Middleton, D.A.; Polya, G.S. Leonardi. Population Hazard Ranking Method for Arsenic in Private Water Supplies: Relation to Bedrock Geology. Int. J. Environ. Res. Public Health 2017, 14, 1490. [CrossRef]

35. Ghosh, R.; Close, R.; McCann, L.; Crabbe, H.; Garwood, K.; Hansell, A.; Leonardi, G. Analysis of hospital admissions due to accidental non-fire related Carbon Monoxide poisoning in England, between 2001 and 2010. J. Public Health 2016, 76-83. [CrossRef]

36. Public Health England. Lead Exposure in Children: Surveillance Reports. Results of Laboratory-based Surveillance of Elevated Blood Lead Co ncentrations in Children in England; 2020. Available online: https://www.gov.uk/government/publications/lead-exposure-in-children-surveillance-reports (accessed on 14 March 2020).

37. Roberts, D.J.; Crabbe, H.; Owodunni, T.; Gordon-Brown, H.; Close, R.; Reshat, S.; Sampson, B.; Ruggles, R.; Dabrera, G.; Busby, A.; et al. Case epidemiology from the first three years of a pilot laboratory-based surveillance system for elevated blood-lead concentrations among children in the UK, 2014-2017: Implications for public health action. J. Public Health 2019, 1-8. [CrossRef]

38. Woods, M.; Crabbe, H.; Close, R.; Studden, M.; Milojevic, A.; Leonardi, G.; Fletcher, T.; Chalabi, Z. Decision support for risk prioritisation of environmental health hazards in a UK city. Environ. Health 2016, 15, 35-47. [CrossRef] [PubMed]

39. Public Health England. Non-infectious Disease Clusters: Investigation Guidelines. Information for Health Protection Specialists on the Investigation of Disease Clusters Suspected of Being Caused by Exposure to Environmental Hazards. 2019. Available online: https://www.gov.uk/government/publications/noninfectious-disease-clusters-investigation-guidelines (accessed on 14 March 2020).

40. Saunders, P.J.; Middleton, J.D.; Rudge, G. Environmental Public Health Tracking: A cost-effective system for characterizing the sources, distribution and public health impacts of environmental hazards. J. Public Health 2017, 39, 506-513. [CrossRef]

41. Résumé des résultats du projet Aphekom 20082011 Des clefs pour mieux comprendre les impacts de la pollution atmosphérique urbaine sur la santé en Europe. Available online: https://www.santepubliquefrance.fr/recherche/\#search=R\%C3\%A9sum\%C3\%A9\%20des\%20r\% C3\%A9sultats\%20du\%20projet\%20Aphekom\%202008-2011.\%20Des\%20clefs\%20pour\%20mieux\% 20comprendre $\% 201$ es \%20impacts \%20de\%20la\%20pollution\%20atmosph\%C3\%A9rique\%20urbaine \% 20sur\%20la\%20sant\%C3\%A9\%20en\%20Europe (accessed on 16 March 2020). 
42. European Commission. Health for the EU in 20 Success Stories: A Selection of Successful Projects Funded by the EU Health Programmes. 2012. Available online: http://www.aphekom.org/c/document_library/get_file? uuid=5f23a693-8154-486f-9f2d-b47ee968bd34\&groupId=10347 (accessed on 14 March 2020).

43. Santé Publique France: Air. Available online: https://www.santepubliquefrance.fr/determinants-de-sante/ pollution-et-sante/air (accessed on 16 March 2020).

44. Fouillet, A.; Bousquet, V.; Pontais, I.; Gallay, A.; Schönemann, C.C. The French Emergency Department OSCOUR Network: Evaluation After a 10-year Existence. Online J. Public Health Inform. 2015, 7, e74. [CrossRef]

45. La surveillance syndromique en Europe le projet européen Triple S. Available online: https://www.santepubliquefrance.fr/recherche/\#search=La\%20surveillance\%20syndromique\%20en \% 20Europe\%20:\%20le\%20projet\%20europ\%C3\%A9en\%20Triple-S. (accessed on 16 March 2020).

46. Motreff, Y.; Pirard, P.; Goria, S.; Labrador, B.; Gourier-Fréry, C.; Nicolau, J.; Le Tertre, A.; Chan-Chee, C. Prehosp Increase in psychotropic drug deliveries after the Xynthia storm, France, 2010. Disaster Med. 2013, 28, 428-433. [CrossRef]

47. Incendie de L'entreprise Lubrizol Surveillance des Recours aux Urgences. Available online: https://www.santepubliquefrance.fr/recherche/\#search=Incendie $\% 20 \mathrm{de} \% 201 \% \mathrm{E} 2 \% 80 \% 99$ entreprise $\%$ 20Lubrizol,\%20surveillance\%20des\%20recours\%20aux\%20urgences (accessed on 16 March 2020).

48. Edokpolo, B.; Allaz-Barnett, N.; Irwin, C.; Issa, J.; Curtis, P.; Green, B.; Hanigan, I.; Dennekamp, M. Developing a Conceptual Framework for Environmental Health Tracking in Victoria, Australia. Int. J. Environ. Res. Public Health 2019, 16, 1748. [CrossRef]

49. Ban, J.; Du, Z.; Wang, Q.; Ma, R.; Zhou, Y.; Li, T. Environmental Health Indicators for China: Data Resources for Chinese Environmental Public Health Tracking. Environ. Health Perspect. 2019, 127. [CrossRef]

50. Chinese Environmental Public Health Tracking CEHT. Available online: https://cepht.niehs.cn:8282/official (accessed on 14 March 2020).

51. CEPHT's Electronic Data Tracking System. Available online: https://cepht.niehs.cn/iehs/goto/blogin (accessed on 14 March 2020).

52. The Canadian Urban Environmental Health Research Consortiumadvancing Research on Urban Living and Human Health. Available online: https://canue.ca/ (accessed on 14 March 2020).

53. KFL\&A. Projects: ACES. Available online: https://www.kflaphi.ca/projects/ (accessed on 14 March 2020).

54. Semenza, J.C.; Sudre, B.; Oni, T.; Suk, J.E.; Giesecke, J. Linking Environmental Drivers to Infectious Diseases: The European Environment and Epidemiology Network. PLoS Negl. Trop. Dis. 2013, 7, e2323. [CrossRef]

55. Environment and Health Information System (ENHIS). Available online: https://gateway.euro.who.int/en/ datasets/enhis/ (accessed on 14 March 2020).

56. Coordinating and Advancing Human Biomonitoring in Europe to Provide Evidence for Chemical Policy Making. Available online: https://www.hbm4eu.eu/ (accessed on 14 March 2020).

57. Fazzo, L.; Minelli, G.; Santis, M.D.; Bruno, C.; Zona, A.; Marinaccio, A.; Comba, P. Mesothelioma mortality surveillance and asbestos exposure tracking in Italy. Ann. Ist. Super Sanità 2012, 48, 300-310. [CrossRef]

58. Zona, A.; Pasetto, R.; Fazzo, L.; Iavarone, I.; Bruno, C.; Pirastu, R.; Comba, P. SENTIERI- Studio epidemiologico nazionale dei territori e degli insediamenti esposti a rischio di inquinamento. Quinto Rapporto. Epidemiol Prev. 2019, 43 (Suppl. 1).

59. Martin-Olmedo, P.; Hams, R.; Santoro, M.; Ranzi, A.; Hoek, G.; de Hoogh, K.; Leonardi, G.S. Environmental and health data needed to develop national surveillance systems in industrially contaminated sites. Epidemiol. Prev. 2018, 42, 6-15.

60. 60. Zona, A.; Iavarone, I.; Buzzoni, C.; Conti, S.; Santoro, M.; Fazzo, L.; Pasetto, R.; Pirastu, R.; Bruno, C.; Ancona, C.; et al. SENTIERI: Epidemiological Study of Residents in National Priority Contaminated Sites. Fifth Report. Epidemiol Prev. 2019, 43 (Suppl. 1), 1-208. [CrossRef]

61. MONITER, Monitoraggio Degli Inceneritori nel Territorio Dell'Emilia-Romgna. Available online: https: //www.arpae.it/moniter/ (accessed on 14 March 2020).

62. Cadum, E.; Forastiere, F. Presentazione del progetto EpiAir e guida alla lettura degli articoli. Epidemiol. Presentazione del Progett. EpiAir e Guid. alla Lett. degli Articoli 2013, 37, 206-208. [PubMed]

63. EU NEIGHBOURS East. Available online: https://www.euneighbours.eu/en/east/stay-informed/events/taiexmulti-country-workshop-environmental-and-public-health-tracking (accessed on 14 March 2020). 
64. Breugelman, O.; Ameling, C.; Marra, M.; Fischer, P.; van de Kassteele, J.; Lijzen, J.; Oosterlee, A.; Keuken, R.; Visser, O.; Houthuijs, D.; et al. Lung Cancer Risk and Past Exposure to Emissions from a Large Steel Plant. J. Environ. Public Health 2013, 2013, 684035. [CrossRef] [PubMed]

65. Franssen, E.A.M.; van Wiechen, C.M.A.G.; Nagelkerke, N.J.D. Lebret EAircraft noise around a large international airport and its impact on general health and medication use. Occup. Environ. Med. 2004, 61, 405-413. [CrossRef]

66. The Burden of Disease from Second-hand Smoke in New Zealand 2016. Available online: http://www.ehinz. ac.nz/assets/Reports/Burden-of-disease-due-to-second-hand-smoke-for-publication-Final-2016-06-28.pdf (accessed on 14 March 2020).

67. What are Environmental Health Indicators? Available online: http://www.ehinz.ac.nz/indicators/overview/ about-the-indicators/ (accessed on 14 March 2020).

68. Public Health Surveillance Information for New Zealand Public Health Actions. Available online: https: //surv.esr.cri.nz (accessed on 14 March 2020).

69. Pacific Decadal Oscillation. Available online: https://en.wikipedia.org/wiki/Pacific_decadal_oscillation (accessed on 14 March 2020).

70. Pacific Public Health Surveillance Network (PPHSN). Available online: https://www.spc.int/taxonomy/term/ 821 (accessed on 14 March 2020).

71. NIHR Health protection Research Unit in Health Impact of Environmental Hazards at King's college London. Available online: http://hieh.hpru.nihr.ac.uk (accessed on 14 March 2020).

72. Health Protection Research Unit in Environmental Change and Health. Available online: http://www.hpruech.nihr.ac.uk (accessed on 14 March 2020).

73. Hansford, K.M.; Fonville, M.; Gillingham, E.L.; Coipan, E.C.; Pietzsch, M.E.; Krawczyk, A.I.; Vaux, A.G.C.; Cull, B.; Sprong, H.; Medlock, J.M. Ticks and Borrelia in urban and peri-urban green space habitats in a city in southern England. Ticks Tick-borne Dis. 2017, 8, 353-361. [CrossRef]

74. Nichols, G.; Lake, I.; Heaviside, C. Climate change and water-related infectious diseases. Atmosphere 2018, 9 , 385. [CrossRef]

75. Cherrie, M.P.C.; Nichols, G.; Iacono, G.L.; Sarran, C.; Hajat, S.; Fleming, L.E. Pathogen seasonality and links with weather in England and Wales: A big data time series analysis. BMC Public Health 2018, 18, 1067. [CrossRef]

76. Lo Iacono, G.; Sarran, C.; Fleming, L.E.; Kessel, A.; Haines, A.; Nichols, G.L. A comparison of weather variables linked to infectious disease patterns using laboratory addresses and patient residence addresses. BMC Infect. Dis. 2017, 18, 198.

77. Friedman, M.; Fernandez, M.; Backer, L.; Dickey, R.; Bernstein, J.; Shrank, K.; Kibler, S.; Stephan, W.; Gribble, M.; Bienfang, P.; et al. An Updated Review of Ciguatera Fish Poisoning: Clinical, Epidemiological, Environmental, and Public Health Management. Mar. Drugs 2017, 15, 72. [CrossRef]

78. White, M.; Alcock, I.; Grellier, J.; Wheeler, B.; Hartig, T.; Warber, S.L.; Bone, A.; Depledge, M.H.; Fleming, L.E. Spending at least $120 \mathrm{~min}$ a week in nature is associated with good health and wellbeing. Sci. Rep. 2019, 9, 7730. [CrossRef] [PubMed]

79. Fleming, L.; Kessel, A.; Murray, V.; Depledge, M.; Leonelli, S.; Tempini, N.; Gordon-Brown, H.; Nichols, G.; Sarren, C.; Vineis, P.; et al. Big Data in Environment and Human Health. Oxf. Res. Encycl. Environ. Sci. 2017, 1-27. [CrossRef]

80. Fleming, L.; Leonardi, G.; White, M.; Medlock, J.; Alcock, I.; Macintyre, H.; Maguire, K.; Nichols, G.; Wheeler, B.; Morris, G.; et al. R Beyond Climate Change and Health: Integrating Broader Environmental Change and Natural Environments for Public Health Protection and Promotion in the UK. Atmosphere 2018, 9, 245. [CrossRef]

81. Health in All Policies: Framework for Country Action. Available online: https://www.who.int/ healthpromotion/frameworkforcountryaction/en (accessed on 14 March 2020).

82. Vardoulakis, S.; Kettle, R.; Cosford, P.; Lincoln, P.; Holgate, S.; Grigg, J.; Kelly, F.; Pencheon, D. Local action on outdoor air pollution to improve health. Int. J. Public Health 2018, 63, 557-565. [CrossRef]

83. Schnarch, B. Ownership, Control, Access, and Possession (OCAP) or Self-Determination Applied to Research: A Critical Analysis of Contemporary First Nations Research and Some Options for First Nations Communities. J. Aborig. Health 2004, 1. [CrossRef] 
84. NRES (National Research Ethics Service). Standard Operating Procedures for Research Ethics Committees, Version September 2018. 2019. Available online: https://www.hra.nhs.uk/planning-and-improvingresearch/policies-standards-legislation/governance-arrangement-research-ethics-committees/ (accessed on 14 March 2020).

85. Hard Data, vs. Soft Data. Available online: https://www.objectivity.com/hard-data-vs-soft-data/ (accessed on 14 March 2020).

86. World Commission on the Ethics of Scientific Knowledge and Technology (COMEST). The Precautionary Principle UNESCO; COMEST: Paris, France, 2005.

87. COMMUNICATION FROM THE COMMISSIONon the Precautionary Principle. Available online: https:// eur-lex.europa.eu/LexUriServ/LexUriServ.do?uri=COM:2000:0001:FIN:EN:PDF (accessed on 14 March 2020).

88. Hart, M.; Dymond, B. A Strong Dose of Climate Skepticism: Seeing Copenhagen as An Opportunity. Policy Options. 2010. Available online: https://policyoptions.irpp.org/magazines/after-copenhagen/a-strong-doseof-climate-skepticism-seeing-copenhagen-as-an-opportunity/ (accessed on 14 March 2020).

89. Odams, S. Ethics in Environmental Epidemiology, In Essentials of Environmental Epidemiology for Health Protection: A Handbook for Field Professionals; Kreis, I.A., Busby, A., Leonardi, G., Meara, J., Murray, V., Eds.; OUP Oxford: Oxford, UK, 2012.

90. Merlo, D.F.; Knudsen, L.E.; Matusiewicz, K.; Niebroj, L.; Vähäkangas, K.H. Ethics in studies on children and environmental health. J. Med. Ethics 2007, 33, 408-413. [CrossRef] [PubMed]

91. WHO. The Power of Cities: Tackling Noncommunicable Diseases and Road Safety; 2019 (WHO/NMH/PND/2019.9). Licence: CC BY-NC-SA 3.0 IGO; World Health Organization: Geneva, The Switzerland, 2019.

92. Climate and Clean Air Coalition Annual Report September 2017-August 2018. 2018. Available online: https://ccacoalition.org/zh-hans/node/2914 (accessed on 14 March 2020).

93. Vardoulakis, S.; Dear, K.; Wilkinson, P. Challenges and Opportunities for Urban Environmental Health and Sustainability: The HEALTHY-POLIS initiative. Environ. Health 2016, 15, S30. [CrossRef] [PubMed]

94. McMichael, A.J.; Friel, S.; Nyong, A.; Corvalan, C. Global environmental change and health: Impacts, inequalities, and the health sector. BMJ Br. Med. J. 2008, 336, 191. [CrossRef]

(C) 2020 by the authors. Licensee MDPI, Basel, Switzerland. This article is an open access article distributed under the terms and conditions of the Creative Commons Attribution (CC BY) license (http://creativecommons.org/licenses/by/4.0/). 